\title{
A RELAÇÃO CONSERVADORA ENTRE PÚBLICO E PRIVADO NA EDUCAÇÃO ESPECIAL: ANÁLISE DE DADOS CENSITÁRIOS ${ }^{1}$
}

\author{
The conservative relationship among public and private in Special Education: \\ analysis of census data
}

\section{La relación conservadora entre público y privado en la Educación Especial: análisis de datos del censo}

\author{
Taísa Grasiela Gomes Liduenha Gonçalves ${ }^{2}$ \\ Beatriz Fonseca Torres ${ }^{3}$ \\ Washington Cesar Shoiti Nozu ${ }^{4}$
}

\begin{abstract}
Resumo
As instituições especializadas se expandiram no Brasil devido à desresponsabilização do Estado com a educação da pessoa com deficiência, ampliando-se a participação filantrópica com o financiamento de instâncias públicas e privadas. A região metropolitana de Belo Horizonte (BH), apresenta marcos históricos na consolidação de ações filantrópicas no campo da Educação Especial. Diante disso, o objetivo desse estudo foi analisar na conjuntura recente (2007 a 2019) o financiamento das matrículas de estudantes da Educação Especial em BH. Para tanto, utilizou-se o banco de matrículas presente no censo escolar da Educação Básica disponibilizado pelo Instituto Nacional de Estudos e Pesquisas Educacionais Anísio Teixeira (INEP). Os resultados mostraram a ampliação das matrículas de estudantes da Educação Especial na Educação Básica, com concentração e crescimento da deficiência intelectual. No que se refere ao financiamento, identificou-se um cenário de municipalização $(48,7 \%)$ e ainda a conservação de instituições e classes especiais sob administração privada de categoria particular e filantrópico.
\end{abstract}

PALAVRAS- CHAVE: Educação especial. Financiamento da educação. Censo escolar.

\footnotetext{
${ }^{1}$ Pesquisa financiada pelo Programa Institucional de Auxílio à Pesquisa de Docentes Recém-Contratados ou Recém-Doutorados da UFMG (edital 11/2017) com vigência de 01/08/2018 a 31/01/2020.

${ }^{2}$ Doutora em Educação Especial pela Universidade Federal de São Carlos- UFSCar. Pós- doutora em Educação pela UEL. Professora adjunta da Faculdade de Educação ( $\mathrm{FaE}$ ) no Departamento de Ciências Aplicadas à Educação (DECAE) da Universidade Federal de Minas Gerais (UFMG). Endereço profissional: Faculdade de Educação (FaE) - UFMG, Sala 1610 - DECAE. Av. Presidente Antônio Carlos, 6627, Pampulha 31270-901, Belo Horizonte/Minas Gerais. Contato profissional; (31) 3409-6225. E-mail: taisaliduenha@icloud.com Orcid: https://orcid.org/0000-0001-5589-584X

${ }^{3}$ Pedagoga pela Universidade Federal de Minas Gerais (UFMG). Endereço profissional: Faculdade de Educação (FaE) - UFMG, Av. Presidente Antônio Carlos, 6627, Pampulha 31270-901, Belo Horizonte/Minas Gerais. E-mail: torresfbia@gmail.com Orcid: https://orcid.org/0000-0002-0001-5312.

${ }^{4}$ Doutor em Educação pela Universidade Federal da Grande Dourados (UFGD). Professor Adjunto da Universidade Federal da Grande Dourados (UFGD). Endereço profissional: Faculdade de Educação (FAED) - UFGD, Rodovia Dourados-Itahum, Km 12, caixa postal 533, 79804-970, Dourados/Mato Grosso do Sul. Contato profissional: (67) 3410-2110. E-mail: wcsn1984@yahoo.com.br Orcid: https://orcid.org/0000-0003-1942-0390
} 


\begin{abstract}
Specialized institutions expanded in Brazil due of lack responsibility from the State with the education of people with disabilities, expanding the philanthropic participation with the financing from public and private instance. The metropolitan region of Belo Horizonte (BH), presents historical landmarks in the consolidation of philanthropic actions in the area of Special Education. The objective of this study was to analyze, in the recent conjuncture (2007 to 2019) the financing of the enrollment of Special Education students in BH. Therefore, was used the enrollment database present in the school census of Basic Education provided by the National Institute of Educational Studies and Research Anísio Teixeira (INEP in portuguese). The results shown an increase in the enrollment of Special Education students in Basic Education, with concentration and increment of intellectual disability. In relation to financing, was identified a municipalization scenario (48.7\%) and also the conservation of institutions and special classes under private administration of particular and philanthropic category.
\end{abstract}

KEYWORDS: Special Education. Education financing. School census.

\title{
Resumen
}

Las instituciones especializadas se expandieron en Brasil debido a la falta de responsabilidad del Estado con la educación de las personas con discapacidad, lo que ha ampliado la participación filantrópica con el financiamiento de organismos públicos y privados. La región metropolitana de Belo Horizonte (BH) presenta hitos históricos en la consolidación de acciones filantrópicas en el campo de la Educación Especial. En vista de esto, el objetivo de este estudio fue analizar, en la coyuntura reciente (2007 a 2019), el financiamiento de la inscripción de estudiantes de la Educación Especial en BH. Para ello, se utilizó el banco de inscripción presente en el censo escolar de Educación Básica puesto a disposición por el Instituto Nacional de Estudos e Pesquisas Educacionais Anísio Teixeira (INEP). Los resultados mostraron un aumento en la inscripción de estudiantes de la Educación Especial en la Educación Básica, con concentración y crecimiento de discapacidad intelectual. Con respecto al financiamiento, se identificó un escenario de municipalización $(48.7 \%)$ y la conservación de instituciones y clases especiales bajo la administración privada de categoría privado y filantrópico.

PALABRAS CLAVE: Educación especial. Financiamiento de la educación. Censo escolar.

\section{INTRODUÇÃOO}

Tradicionalmente, a Educação Especial se constituiu como um sistema paralelo, por meio de instituições especializadas destinadas ao atendimento de pessoas com deficiência, com profissionais, serviços e recursos específicos (GLAT; BLANCO, 2009). No Brasil, as instituições especializadas caracterizam-se pela filantropia e assistencialismo, sendo estruturadas, principalmente, sob o regime jurídico de natureza privada, sem fins lucrativos, com captação de recursos públicos por meio de convênios e de subvenções com a União, os estados e os municípios (LAPLANE; CAIADO; KASSAR, 2016; GARCIA, 2017).

Os poucos espaços públicos de atendimento educacional às pessoas com deficiência, sobretudo as classes especiais e as oficinais pedagógicas, criadas mormente nas escolas estaduais, a partir da década de 1970, por meio do Centro Nacional de Educação Especial (CENESP), foram sendo fechadas a partir da década de 1990 (KASSAR, 2012). 
Nesse contexto, três movimentos confluíram para o recuo do "público" e para o avanço do "privado" na prestação de serviços especializados, conforme Kassar (2012, p. 840-841): a) "a disseminação do discurso da inclusão escolar e a identificação das matrículas unicamente em espaços especializados como atitudes discriminatórias" (p. 840), questionando o funcionamento de classes especiais; b) o processo de municipalização do ensino obrigatório, cuja implementação não previa "espaços públicos para atendimento educacional aos alunos com deficiências, visto que esses espaços estavam historicamente ligados às escolas estaduais (classes especiais e oficinas pedagógicas)" (p. 840); o reconhecimento, por parte de agências multilaterais, da onerosidade aos cofres públicos da manutenção de instituições especializadas, incentivando, dessa forma, a "participação das instituições privadas nas ações sociais, principalmente após a reforma de aparelho de Estado, implantada no Governo de Fernando Henrique Cardoso, em 1995, e com a instituição do marco legal do Terceiro Setor" (p. 841).Assim, "se a presença do setor privado é reconhecida pelo poder público como uma colaboração importante para a efetivação de formas diferenciadas de atendimento, para o setor privado, a busca por recursos públicos é fundamental para sua existência" (LAPLANE; CAIADO; KASSAR, 2016, p. 42).

Esses movimentos vão configurando relações complexas e de interdependência entre o público e o privado na Educação Especial, ainda que sob a égide da perspectiva política da educação inclusiva (LAPLANE; CAIADO; KASSAR, 2016). Nessas tramas, cria-se, comumente, entre a população a falsa impressão de que essas instituições filantrópico-assistenciais são, pela gratuidade dos serviços, necessariamente, públicoestatais (KASSAR, 2011; SOTO et al., 2012), fortalecendo, assim, a sua presença e permanência nos processos político-decisórios relacionados à educação da pessoa com deficiência (SANTOS; GONÇALVES; MANTOVANI, 2015; GARCIA, 2017).

Garcia (2017) analisa as forças em disputas na atual conjuntura: de um lado, a "tradição", representada pelas instituições especializadas privado-assistenciais; de outro lado, a "inovação", identificada com a proposta inclusiva e transmutada em atendimento, complementar/suplementar, em salas de recursos multifuncionais, com recursos tecnológicos. Contudo, para a autora "tanto as forças da 'tradição', como as forças da 'inovação' guardam um projeto social e educacional conservador”' (GARCIA, 2017, p. 40).

[...] O caráter conservador das forças da "tradição" é bastante conhecido entre nós, permeado por um poder privado e filantrópico, com caráter assistencial, e atuando com recursos públicos. Já em relação às forças da "inovação" podemos pensar que a articulação da educação especial à escola de educação básica se realiza em uma conjuntura na qual a privatização, o tecnicismo, a precarização e intensificação do trabalho docente, a avaliação da qualidade pelo ranqueamento do desenvolvimento de habilidades e competências cognitivas e socioemocionais com inspiração na teoria do capital humano visando preparar para o trabalho simples constituem o espírito da formação escolar. Uma formação escolar para o consentimento ativo acerca da formação social capitalista no atual estágio de desenvolvimento do modo de produção, tendo em vista a ofensiva do capital ao trabalho e à formação da educação destinada aos filhos dos trabalhadores como projeto de dominação e de direção. Nenhuma das forças em litígio propõe uma formação humana abrangente com vistas a formulação de uma leitura crítica consistente da realidade social e que permita vislumbrar um horizonte para além da desigualdade constitutiva da formação social capitalista. (GARCIA, 2017, p. 40). 
Ainda, o conservadorismo na Educação Especial é mantido tanto pela "tradição" quanto pela "inovação", ao centrar-se numa concepção medicalizante da deficiência. Isso porque, se as instituições especializadas atuam, historicamente, com procedimentos focalizados nos indivíduos com deficiência, as salas de recursos multifuncionais previstas na política de inclusão escolar também os fazem, com atendimentos concentrados nos supostos déficits dos alunos com deficiência, sem, contudo, alterar as estruturas educacionais e/ou sociais (MENDES, 2019).

Considerando que o município de $\mathrm{BH}$ apresenta ações históricas na área da Educação Especial, discorreremos sucintamente sobre esses processos políticos que influenciaram a consolidação desse financiamento público-privado.

\section{A constituição do público-privado na Educação Especial em Belo Horizonte}

Ao retomarmos a história da Educação Especial no município de $\mathrm{BH}$, identificamos a criação do Instituto São Rafael (1926) como um marco, sob dependência administrativa estadual, com enfoque na educação de pessoas com deficiência visual e cegueira (LEÃO JUNIOR; GATTI, 2016).

Jannuzzi (2012) e Kassar (2013) apresentam, em seus estudos, que a história da Educação Especial em BH e região foi influenciada pelas ações de Helena Antipoff, psicóloga e educadora russa, que veio para o Brasil a convite do estado mineiro. As instituições para o atendimento de pessoas com deficiência, tais como a Sociedade Pestalozzi de BH (1932), Instituto Pestalozzi (1935) e Fazenda do Rosário (1940) foram criadas e subsidiadas na relação público-privado. Nas palavras de Borges e Barbosa (2019, p. 175) "a partir da filantropia, iniciada com a criação da $\mathrm{SPMG}^{5}$ em 1932, Antipoff construiu instituições que atravessaram o tempo e permanecem em atividade até hoje, além de costurar alianças com diferentes governos e agentes públicos".

$\mathrm{O}$ atendimento filantropo para as pessoas com deficiências se ampliou no estado mineiro com o Associação de Pais e Amigos dos Excepcionais (APAE), na década de 1950. Em BH, essa instituição foi criada em $1961^{6 .}$

Mattos (2005, p. 95), ao realizar uma análise do percurso da Educação Especial em Minas Gerais, afirma que "desde a vinda da psicóloga Helena Antipoff para o Brasil até o final da década de 90, esta modalidade de ensino assumiu predominantemente um caráter segregador e assistencialista com relação às pessoas com deficiência”.

Evidenciava-se no período de 1970 e 1980 altos índices de repetência, evasão e encaminhamentos às classes especiais. Por conseguinte, em 1983 foi realizado o I Congresso Mineiro de Educação com o objetivo de universalizar a escola pública (MATTOS, 2005).

No final da década de 1980, foi criado pela Secretaria Municipal de Educação de BH (SMED-BH) o Projeto "Livre Trânsito" que tinha como objetivo a instalação de Centros de Educação Especial nas nove regionais administrativas do município, apoiando a integração dos alunos da Educação Especial que frequentavam as escolas comuns. Porém, os Centros não foram materializados devido os recursos orçamentários e foram substituídos pela implantação de três escolas municipais de Educação Especial (SILVA, 2005).

\footnotetext{
${ }^{5}$ Sigla referente à Sociedade Pestalozzi de Minas Gerais.

${ }^{6}$ Informações disponíveis em: <https://apaebh.org.br>. Acesso em: 26 abr. 2020.
} 
Em decorrência dos acordos internacionais assumidos pelo Brasil na década de 1990 e a disseminação do conceito escola inclusiva proposta em documentos e políticas municipais e estaduais, a Rede Municipal de Educação de BH (RMEBH), em 1995, desenvolveu o Projeto Escola Plural buscando ressignificar o cotidiano escolar, rever o percurso de exclusão social e consequentemente, ampliar as matrículas de alunos da educação especial nas escolas da rede municipais (SILVA, 2005; FERREIRA, 2009). "Deste modo, escolas comuns da Rede Municipal passaram a ser desafiadas a atender às crianças com deficiência, condutas típicas e/ou dificuldades de aprendizagem, até então encaminhadas para atendimento exclusivamente nas escolas especiais" (SILVA, 2005, p. 98).

Entre os anos de 2001 a 2005, a Secretaria da Educação de Minas Gerais (SEEMG) desenvolveu o Programa de Apoio à Educação para a Diversidade, com o objetivo de implantar a proposta da Educação Inclusiva nas escolas da rede estadual. Na sequência criou o Projeto Incluir: Diretrizes da Educação Inclusiva em Minas Gerais, com o intuito de garantir o acesso, a permanência e o desenvolvimento dos alunos da Educação Especial nas escolas regulares, inclusive com a implementação do atendimento educacional especializado (AEE) (SANTOS, 2004; MATTOS, 2005; SANTOS, 2013).

Em 2014, a SEE-MG publicou o Guia de Orientação da Educação Especial (2014) que especifica os estudantes da Educação Especial $^{7}$ e elucida sobre o processo escolar, recursos de acessibilidade, atribuições do AEE, formação de professores, intersetorialidade e monitoramento das atividades da Educação Especial no estado. Particularmente sobre as escolas de Educação Especial, o Guia orienta que

\begin{abstract}
[...]frente ao processo de inclusão, deve transformar-se, romper com o papel assistencialista, cujas prioridades eram o cuidado pessoal, a clínica e a socialização dos alunos com deficiências e transtornos globais do desenvolvimento, organizando-se para o oferecimento de apoio às escolas comuns, através de capacitações dos professores, suporte de recursos didáticos e tecnológicos específicos e oferecimento de complementação curricular aos alunos público da Educação Especial que estão matriculados nas escolas de ensino comum (MINAS GERAIS, 2014, p. 25)
\end{abstract}

Em face desses apontamentos, entende-se que "as análises dos indicadores educacionais podem suscitar novas inquietações, desvelar uma realidade marcada pelo assistencialismo e apontar outras possibilidades e desafios para a educação escolar de pessoas com deficiências" (SANTOS; GONÇALVES; MANTOVANI, 2015, p. 362).

Assim, delimitando a abrangência e a contingência investigativa, o presente artigo objetiva analisar na conjuntura recente (2007 a 2019) o financiamento das matrículas de estudantes da Educação Especial em Belo Horizonte (BH).

\title{
Percurso metodológico
}

Gatti (2004) problematiza a falta de tradição das pesquisas educacionais no Brasil com metodologias quantitativas e destaca a necessidade de nos arriscarmos e tentarmos interpretar dimensões sociais e educacionais apresentadas pelos dados

\footnotetext{
${ }^{7}$ Pessoas com deficiência, transtornos globais do desenvolvimento e altas habilidades/ superdotação.
} 
estatísticos. Essa produção de informações possibilitam um monitoramento das ações governamentais e uma averiguação das mudanças na realidade social (SOLIGO, 2012).

Os dados quantitativos permitem interpretações da realidade social. Soligo (2012, p.18) ilustra que na educação, "os indicadores são estatísticas que possibilitam formular avaliações sobre aspectos essenciais do funcionamento dos sistemas educativos".

O censo escolar é um instrumento que permite acompanhar a situação educacional brasileira e a efetividade das políticas públicas, servindo de base no repasse de recursos do governo federal. Conforme Meletti e Bueno (2013, p. 77), "trata-se do principal instrumento de coleta de informações sobre a educação básica, que abrange as suas diferentes etapas e modalidades, reunindo dados sobre estabelecimentos, matrículas, funções docentes, movimento e rendimento escolar".

Diante disso, coletou-se nos microdados do censo escolar da Educação Básica as matrículas de alunos da Educação Especial no período de 2007 a 2019 (BRASIL, MEC, INEP, 2007-2019), disponibilizadas no site do INEP para download. Para a leitura desses dados foi utilizado o Software IBM SPSS 20, plataforma disponibilizada pela Universidade Federal de Minas Gerais (UFMG).

Inicialmente, selecionou-se o código do município das escolas de $\mathrm{BH}$ (CO_MUNICÍPIO). Realizou-se uma frequência das matrículas de estudantes da Educação Especial de acordo com as variáveis: IN_NECESSIDADE_ESPECIAL ${ }^{8}$; IN_DEF_AUDITIVA, IN_SURDEZ, IN_CEGUEIRA, IN_BAIXA_VISAO, IN_DEF_FISICA e IN_DEF_INTELECTUAL. Na sequência foi feito um cruzamento do total de matrículas de estudantes da Educação Especial (IN_NEE) segundo a dependência administrativa (TP_DEPENDENCIA- Federal, Estadual, Municipal e Privada) e categoria da escola privada (TP_CATEGORIA_ESCOLA_PRIVADAParticular, Comunitária, Confessional e Filantrópica).

Para especificar a análise foi realizado no ano de 2019, o mais recente no momento do estudo, um cruzamento das matrículas de alunos da Educação Especial segundo as modalidades de ensino (IN_REGULAR, IN_ESPECIAL_EXCLUSIVA ${ }^{9}$ e IN_EJA) e as dependências administrativas. Também foi feito um cruzamento dessas matrículas com a modalidade de ensino especial e categoria da escola privada. Após a coleta, esses dados foram tabulados em planilha de Excel.

A partir destes procedimentos metodológicos, apresentamos os resultados e análises sobre o financiamento das matrículas da Educação Especial em BH segundo os dados do censo escolar (2007-2019).

\section{O financiamento das matrículas de Educação Especial em BH}

Ao focar a análise nos dados de matrículas de alunos com deficiência (visual ${ }^{10}$, auditiva, física e intelectual) do censo escolar no período de 2007 a 2019, identificou-se a concentração de alunos com deficiência intelectual conforme apresenta a Figura 1.

\footnotetext{
${ }^{8}$ Refere-se a todos os estudantes da Educação Especial: com deficiência, transtorno do espectro autista ou altas habilidades/superdotação (BRASIL, 2019).

${ }^{9}$ Refere-se a escolas e classes especiais (BRASIL, 2019).

${ }^{10}$ Os dados de deficiência auditiva são resultantes da somatória entre deficiência auditiva e surdez, assim como a visual, sendo a somatória de cegueira e baixa visão.
} 
Figura 1: Número total de estudantes da Educação Especial e segundo o tipo de deficiências

Belo Horizonte (2007-2019)

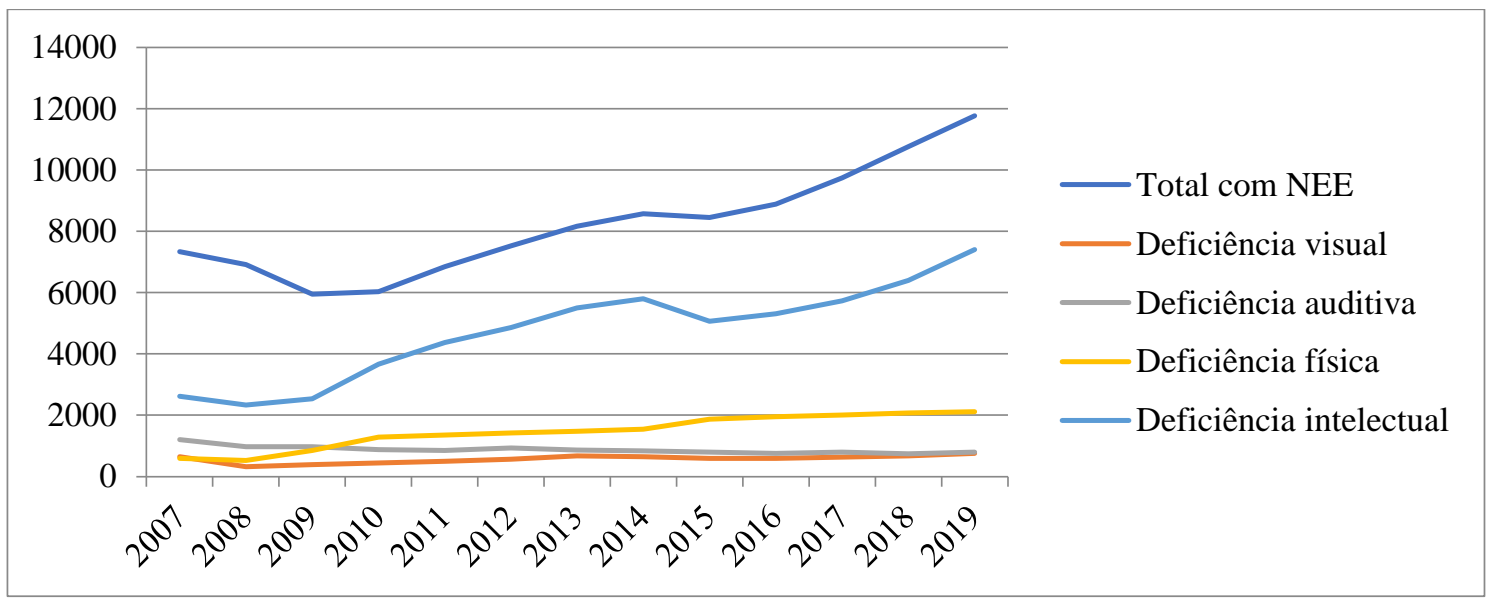

Fonte: elaborado pelos autores com base nos microdados do Censo Escolar da Educação Básica de 2007 a 2019.

Os resultados mostram um aumento de 60,3\% nas matrículas de estudantes da Educação Especial na Educação Básica no município, comparando o ano de 2019 com o de 2007. A média das matrículas de alunos com deficiência intelectual (70\%), ao longo dos anos, sobressaiu com relação à deficiência física $(19,2 \%)$, seguida pela deficiência auditiva $(11,4 \%)$ e visual $(7,4 \%)$.

A prevalência de matrículas de alunos com deficiência mental/intelectual ${ }^{11}$ tem sido uma constante nos registros dos Censos Escolares (MELETTI; BUENO, 2013), tanto na rede pública como na privada (LAPLANE, 2015). Tais dados necessitam ser problematizados, considerando a "[...] possibilidade daqueles que não aprendem na escola estarem sendo rotulados inadequadamente de deficientes intelectuais, conservado práticas comuns das escolas brasileiras em épocas não inclusivas" (MELETTI; BUENO, 2013, p. 83).

Para dimensionar o cômputo das matrículas da Educação Especial na Educação Básica segundo o financiamento apresenta-se a Figura 2.

\footnotetext{
${ }^{11}$ As nomenclaturas alteram-se nos censos da Educação Básica. 
Figura 2: Número de matrículas de estudantes da Educação Especial que frequentam a Educação Básica segundo a dependência administrativa em Belo Horizonte (2007-2019)

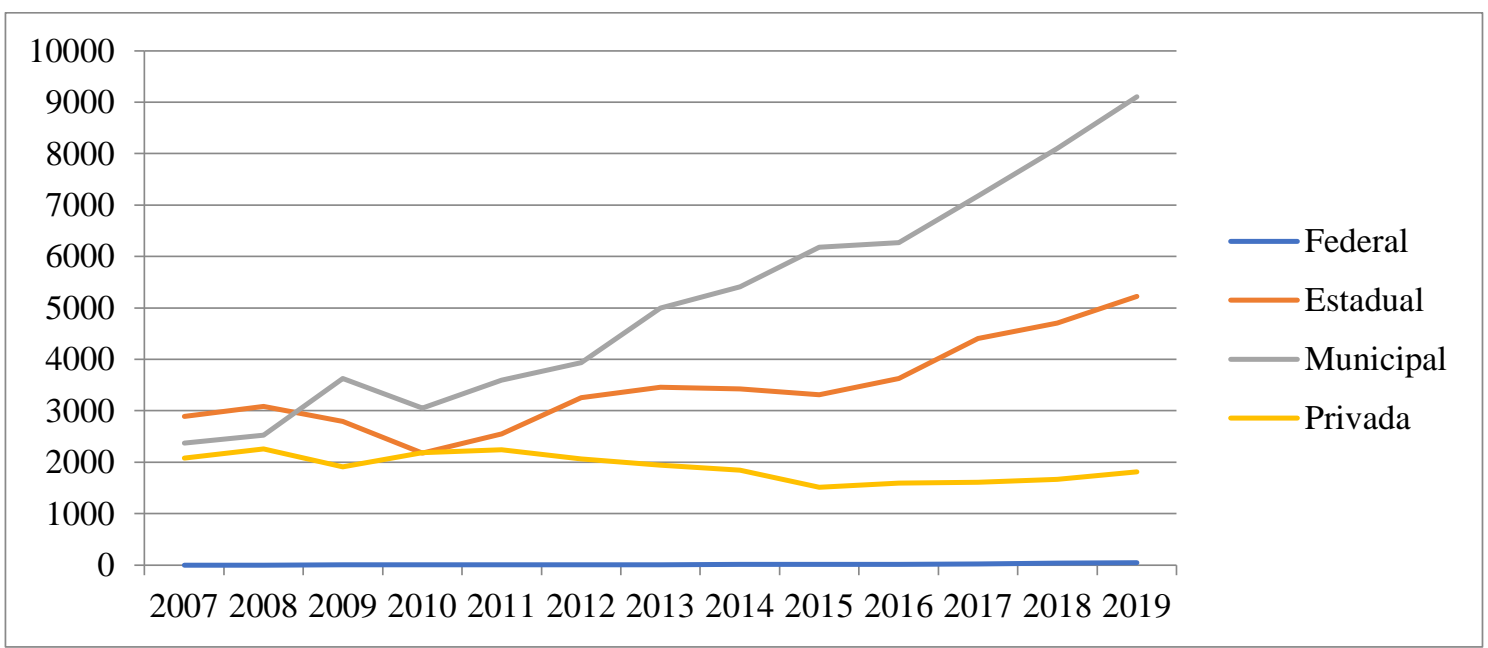

Fonte: elaborado pelos autores com base nos microdados do Censo Escolar da Educação Básica de 2007 a 2019.

Identifica-se, a partir da média no período, a predominância da dependência administrativa municipal $(48,7 \%)$, seguida pela estadual $(32,9 \%)$, privada $(18,2 \%)$ e federal $(0,14 \%)$.Estes dados evidenciam que o processo de municipalização do ensino também tem produzido efeitos nas matrículas dos estudantes da Educação Especial (KASSAR, 2012).

$\mathrm{O}$ município de $\mathrm{BH}$ apresenta instituições especiais municipais e estaduais, exemplifica-se com Escola Municipal de Ensino Especial Frei Leopoldo, Escola Estadual Dona Argentina Vianna Castelo Branco, Escola Estadual Francisco Sales (atendimento especializado a pessoas com surdez) e Instituto Estadual São Rafael (atendimento especializado a pessoas com deficiência visual).

Para compreendermos o financiamento das matrículas de alunos da Educação Especial em escolas privadas da Educação Básica, apresenta-se a Figura 3.

Figura 3: Número de matrículas de estudantes da Educação Especial na Educação Básica por categoria da escola privada em Belo Horizonte (2007-2019)

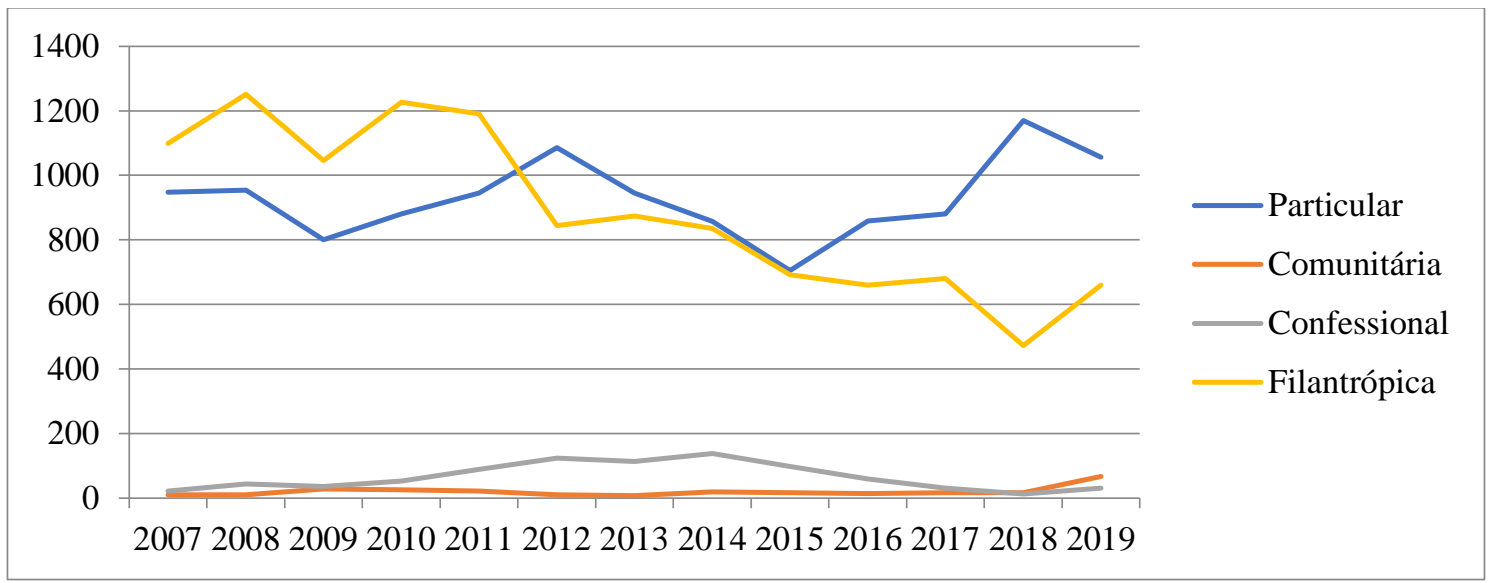

Fonte: elaborado pelos autores com base nos microdados do Censo Escolar da Educação Básica de 2007 a 2019. 
No ano de 2019, a maior parte das matrículas de estudantes com NEE no ensino privado permaneceu sob a competência da categoria particular, com 58,2\% (1056), enquanto a filantrópica atendia $36,4 \%$ (660) das matrículas. O convênio privado é garantido pela distribuição de recursos do Fundo de Manutenção e Desenvolvimento da Educação Básica e de Valorização dos Profissionais da Educação (FUNDEB) (LAPLANE; CAIADO; KASSAR, 2016).

Esses dados indicam a continuidade do setor privado, sobretudo particular e filantrópico, mesmo com a vigência de uma política na perspectiva inclusiva. Nas palavras de Michels e Garcia (2014, p.168):

\begin{abstract}
O termo "sistema educacional inclusivo" vem carrear sentidos de valorização do setor privado na educação, nas suas faces mercantil e assistencial. Também confunde a noção de sistema educacional com a proposição de sistemas operacionais de gestão e controle da educação nacional, apresentados com uma aura de eficiência e transparência na distribuição dos recursos financeiros.
\end{abstract}

A partir disso, buscou-se identificar nas matrículas de estudantes da Educação Especial a relação entre modalidade de ensino e a dependência administrativa, conforme mostra a Tabela 1.

Tabela 1: Número de matrículas de estudantes da Educação Especial segundo a modalidade de ensino e a dependência administrativa no município de Belo Horizonte (2019)

\begin{tabular}{|c|c|c|c|}
\hline $\begin{array}{c}\text { Tipo de dependência } \\
\text { administrativa }\end{array}$ & Ensino Regular & Educação Especial & EJA \\
\hline Federal & 32 & 0 & 5 \\
\hline Estadual & 3557 & 371 & 357 \\
\hline Municipal & 5686 & 358 & 311 \\
\hline Privada & 1505 & 454 & 256 \\
\hline
\end{tabular}

Fonte: elaborado pelos autores com base nos microdados do Censo Escolar da Educação Básica de 2007 a 2019.

No ano de 2019, a concentração das matrículas estava no ensino regular, sobretudo com dependência administrativa municipal e federal.

Outro dado a comentar é a necessidade de discussões e estudos sobre o financiamento na interface EJA e Educação Especial, haja visto uma tendência de aumento dessas matrículas no Brasil e a construção da EJA Especial em classes e instituições segregadas (GONÇALVES; BUENO; MELETTI, 2013). 
Ao focar nas matrículas em instituições e classes especiais (Modalidade Especial) evidencia-se a concentração 38,4\% (454) no setor privado. Conforme Laplane, Caiado e Kassar (2016, p. 51),

\begin{abstract}
Na educação especial, o setor privado tem longa tradição no Brasil e presença constante nas políticas públicas. Embora a política inclusiva esteja promovendo a matrícula da população alvo dessa modalidade educacional nas escolas regulares e classes comuns e esse atendimento esteja ocorrendo principalmente pelas escolas públicas, as instituições com atuação exclusiva na educação especial, que atendem majoritariamente aos alunos matriculados em escolas especiais, têm recebido recursos públicos de forma crescente.
\end{abstract}

Em sentido convergente, Soto et al. (2012), em estudo realizado sobre o financiamento em um município paulista, indicam que as despesas com a Educação Especial, quando comparadas às etapas da Educação Básica e às outras modalidades de ensino, são pouco onerosas ao orçamento geral, ao passo que a disponibilização de recursos para as instituições especializadas filantrópicas é volumosa.

Ao direcionar a análise para as matrículas localizadas em classes e instituições especiais segundo a categoria da escola privada, apresenta-se a Tabela 2.

Tabela 2: Número de matrículas de estudantes na modalidade Educação Especial segundo a categoria da escola privada (2019)

\begin{tabular}{|c|c|}
\hline Categoria da escola privada & Educação Especial \\
\hline Particular & 183 \\
\hline Comunitária & 19 \\
\hline Confessional & 0 \\
\hline Filantrópica & 252 \\
\hline
\end{tabular}

O número de matrículas em classes e instituições especiais se concentram na filantropia $(55,50 \%)$ seguido pelo particular $(40,30 \%)$.

No cenário da educação inclusiva, Mendes (2019) elenca três críticas recorrentes sobre a responsabilização das instituições especializadas filantrópico-assistenciais pela educação das pessoas com deficiência: a desresponsabilização do Estado e da escola pública pela educação desta parcela da população, induzindo a ideia de que a educação da pessoa com deficiência não se trata de um direito, mas de uma benevolência; a potencialização da segregação e da discriminação em razão da deficiência; e o mascaramento de fins assistencialistas sob a denominação de educacionais, considerando a restrita ênfase no processo de escolarização dos atendidos.

Em análise das escolas vinculadas a uma instituição especializada no Brasil, o estudo de Santos, Gonçalves e Mantovani (2015, p. 366) informa a predominância da categoria filantrópica, destacando "que esta é uma característica histórica dos espaços 
segredos. Observamos que esta participação filantrópica tão demarcada na Educação Especial é reflexo da sociedade capitalista, que por interesses "partilha" a responsabilidade social do estado com a sociedade civil".

Essa realidade de caráter filantrópico em classes e instituições especiais em $\mathrm{BH}$ converge para o assistencialismo e segregação, com o distanciamento da efetivação do conhecimento sistematizado que possibilita a emancipação humana.

\section{ALGUMAS CONSIDERAÇÕES}

Historicamente, as instituições privado-assistenciais têm atuado, no Brasil, para o atendimento de pessoas com deficiência. A ênfase dessa atuação tem se dado tanto na arena política decisória da agenda da Educação Especial quanto na prestação direta de serviços especializados, por meio de parcerias público-privadas.

A tendência crescente das matrículas de estudantes com deficiência intelectual na Educação Básica de BH precisa ser problematizada, rompendo com classificações deterministas baseadas por exemplo na condição socioeconômica do estudante.

A despeito da proposta de inclusão dos estudantes da Educação Especial nas escolas comuns, as instituições especializadas, sobretudo as de caráter filantrópico, ainda representam uma força presente e latente nas políticas públicas educacionais.

Se, de um lado, as políticas de inclusão têm potencializado as matrículas dos estudantes da Educação Especial nas escolas comuns; por outro lado, as instituições especializadas continuam autorizadas, pela via legal, a escolarizar os alunos com deficiência, com possibilidade de captação de recursos públicos nas três esferas da federação. Assim, conserva-se todo um modus operandi na trajetória da Educação Especial brasileira.

Além disso, ao centralizar o indivíduo como foco dos atendimentos, tanto a "tradição" das instituições especializadas como a "inovação" da inclusão escolar, operacionalizada via salas de recursos multifuncionais, conservam o modelo médico clínico da deficiência, sem alterações dos sistemas sociais e educacionais.

\section{REFERÊNCIAS}

BORGES, Adriana Araújo Pereira; BARBOSA, E. A. N. . Helena Antipoff e a Sociedade Pestalozzi de Minas Gerais: filantropia e ciência em prol dos anormais. História, Ciências, Saúde-Manguinhos, v. 26, p. 163-177, 2019.

Ministério da Educação. Instituto Nacional de Estudos e Pesquisas

Educacionais Anísio Teixeira - INEP. Censo Escolar da Educação Básica- 2007.

BRASIL. Ministério da Educação. Instituto Nacional de Estudos e Pesquisas

Educacionais Anísio Teixeira - INEP. Censo Escolar da Educação Básica - 2008.

. Ministério da Educação. Instituto Nacional de Estudos e Pesquisas

Educacionais Anísio Teixeira - INEP. Censo Escolar da Educação Básica - 2009.

Educação e Fronteiras On-Line, Dourados/MS, | v. 10, n. 30,| p. 185-199, set /dez 2020 
Ministério da Educação. Instituto Nacional de Estudos e Pesquisas

Educacionais Anísio Teixeira - INEP. Censo Escolar da Educação Básica - 2010.

Ministério da Educação. Instituto Nacional de Estudos e Pesquisas

Educacionais Anísio Teixeira - INEP. Censo Escolar da Educação Básica - 2011.

Ministério da Educação. Instituto Nacional de Estudos e Pesquisas

Educacionais Anísio Teixeira - INEP. Censo Escolar da Educação Básica- 2012.

Ministério da Educação. Instituto Nacional de Estudos e Pesquisas

Educacionais Anísio Teixeira - INEP. Censo Escolar da Educação Básica - 2013.

Ministério da Educação. Instituto Nacional de Estudos e Pesquisas

Educacionais Anísio Teixeira - INEP. Censo Escolar da Educação Básica - 2014.

Ministério da Educação. Instituto Nacional de Estudos e Pesquisas

Educacionais Anísio Teixeira - INEP. Censo Escolar da Educação Básica - 2015.

Ministério da Educação. Instituto Nacional de Estudos e Pesquisas

Educacionais Anísio Teixeira - INEP. Censo Escolar da Educação Básica - 2016.

. Ministério da Educação. Instituto Nacional de Estudos e Pesquisas

Educacionais Anísio Teixeira - INEP. Censo Escolar da Educação Básica- 2017.

. Ministério da Educação. Instituto Nacional de Estudos e Pesquisas

Educacionais Anísio Teixeira - INEP. Censo Escolar da Educação Básica-2018.

Ministério da Educação. Instituto Nacional de Estudos e Pesquisas

Educacionais Anísio Teixeira - INEP. Censo Escolar da Educação Básica- 2019.

FERREIRA, Cláudia Silva. A Escola Plural anos depois: a voz de gestores e docentes. Dissertação (Mestrado em Educação) - Universidade Federal de Minas Gerais, Belo Horizonte, 2009.

GARCIA, Rosalba Maria Cardoso. Disputas conservadoras na política de educação especial na perspectiva inclusiva. In: GARCIA, Rosalba Maria Cardoso (Org.). Políticas de educação especial no Brasil no início do século XXI. Florianópolis:

UFSC/CED/NUP, 2017, p. 19-66. 
GATTI, Bernadete. A. Estudos quantitativos em educação. Educação e Pesquisa, São Paulo, v. 30, p.11-30, 2004.

GLAT, Rosana; BLANCO, Leila de Macedo Varela. Educação especial no contexto de uma educação inclusiva. In: GLAT, Rosana (Org.). Educação inclusiva: cultura e cotidiano escolar. 2. ed. Rio de Janeiro: 7 Letras, 2009, p. 15-35.

GONÇALVES, Taísa Grasiela Gomes Liduenha. BUENO, José Geraldo Silveira ; MELETTI, Silvia Márcia Ferreira. Matrículas de alunos com deficiência na EJA: Uma análise dos indicadores educacionais brasileiros. Revista Brasileira de Política e Administração da Educação, v. 29, p. 407-427, 2013.

JANNUZZI, Gilberta de Martinho. A educação do deficiente no Brasil:dos primórdios ao início do século XXI. Campinas, SP: Autores Associados, 2012.

KASSAR, Mônica de Carvalho Magalhães. Educação especial na perspectiva da educação inclusiva: desafios da implantação de uma política nacional. Educar em Revista, Curitiba, Brasil, n. 41, p. 61-79, jul./set. 2011.

KASSAR, Mônica de Carvalho Magalhães. Educação Especial no Brasil: desigualdades e desafios no reconhecimento da diversidade. Educação \& Sociedade, Campinas, v. 33, n. 120, p. 833-849, jul. -set. 2012.

KASSAR, Mônica de Carvalho Magalhães. Uma breve história da educação das pessoas com deficiências no Brasil. In: Silvia Márcia Ferreira Meletti; Mônica de Carvalho Magalhães Kassar. (Org.). Escolarização de alunos com deficiências: desafios e possibilidades. 1ed.Campinas: Mercado de Letras, 2013, v. 1, p. 33-76.

LAPLANE, Adriana Lia Friszman de. O que os dados do censo escolar revelam sobre as barreiras à inclusão? Educação e Fronteiras On-Line, Dourados/MS, v. 5, n. 14, p. 21-41, maio/ago. 2015.

LAPLANE, Adriana Lia Friszman de; CAIADO, Katia Regina Moreno; KASSAR, Mônica de Carvalho Magalhães. As relações público-privado na educação especial: tendências atuais no Brasil. Revista Teias, v. 17, n. 47, p. 41-55, jul./set. 2016.

LEÃO JUNIOR, Wandelcy; GATTI, Giseli Cristina do Vale. História de uma instituição educacional para o deficiente visual: o Instituto de Cegos do Brasil Central de Uberaba (Minas Gerais, Brasil, 1942-1959) . História da Educação (Online), Porto Alegre v.20 n. 50 set./dez., p.389-409, 2016. 
MATTOS, GracieleFernandes Ferreira. A proposta de educação inclusiva da secretaria de estado da educação de Minas Gerais: o PAED em questão. 261 p. Dissertação (Mestrado em Educação). Universidade Federal de Juiz de Fora, Minas Gerais, 2005.

MELETTI, Silvia Márcia Ferreira; BUENO, José Geraldo Silveira. A escolarização de alunos com deficiência intelectual: análise dos indicadores educacionais brasileiros. In: MELETTI, Silvia Márcia Ferreira; BUENO, José Geraldo Silveira (Orgs.). Políticas públicas, escolarização de alunos deficiência e a pesquisa educacional. Araraquara, SP: Junqueira \& Marin, 2013, p. 75-86.

MENDES, Enicéia Gonçalves. A política de educação inclusiva e o futuro das instituições especializadas no Brasil. Arquivos Analíticos de Políticas Educativas, 27(22), 2019.

MICHELS, Maria Helena; GARCIA, Rosalba Maria Cardoso. Sistema educacional inclusivo: conceito e implicações na política educacional brasileira. Caderno Cedes, Campinas, v. 34, n. 93, p. 157-173, maio-ago. 2014.

MINAS GERAIS. Guia de orientação da educação especial na rede estadual de ensino de Minas Gerais. Subsecretaria de desenvolvimento da Educação Básica, versão 3, 2014.

SANTOS, Natália Gomes dos; GONÇALVES, Taísa Grasiela Gomes Liduenha; MANTOVANI, Juliana Vechetti. O público e o privado na educação especial: o caso da Sociedade Pestalozzi no Brasil. Revista Cocar, Belém, v. 9. n. 18, p. 350-377, Jul./Dez. 2015.

SANTOS, Cristiane S. Políticas públicas de educação para alunos portadores de necessidades educativas especiais no ensino regular de Minas Gerais nos anos de 1990: inclusão ou exclusão educacional. Dissertação (Mestrado em Educação) Universidade Federal de Uberlândia,Uberlândia, 2004.

SANTOS, Maressa Valente dos. A implantação do Projeto Incluir e o seu gerenciamento nasuperintendência regional de ensino de Carangola/Minas Gerais. Dissertação (Mestrado professional em ensino de ciência) - Universidade Federal de Itajubá, Itajubá, 2013.

SILVA, Jerusa de Pinho Tavares. Escola plural e educação inclusiva: diversos olhares, múltiplos sentidos. Dissertação (Mestrado em Educação) - Universidade Federal de Juiz de Fora, Juiz de Fora, 2005. 
SOLIGO, Valdecir. Indicadores: conceito e complexidade do mensurar em estudos de fenômenos sociais. Estudos em avaliação educacional, v. 23, n. 52, p. 12-25, 2012.

SOTO, Ana Paula de Oliveira Moraes et al. Financiamento da educação especial no Brasil na arena do público e do privado. Poiésis, Tubarão, v. 6, n. 10, p. 359-376, 2012.

Recebido: 05/05/2020

Aprovado: 10/07/2020 